\title{
The Diffuse Reflection Radiation from the Atmosphere Bounded by the Hybrid Surface of a Diffuse and Specular Reflector
}

\author{
By Tsutomu Takashima* \\ Atmospheric Environment Service, Toronto, Canada \\ (Manuscript received 14 July 1975, in revised form 30 September 1975)
}

\begin{abstract}
The intensity and the degree of polarization of the radiation diffusely reflected by an inhomogeneous atmosphere are computed by using the adding method (Takashima et al., 1975), where the atmosphere is composed of twelve homogeneous composite layers. The atmosphere-ground system used for the numerical computations is such a realistic model that the effect of scattering due to aerosols distribution with height and the absorption effect by ozone are taken into account. In addition, the atmosphere is bounded by a hybrid surface of a diffuse and specular reflector. In this paper, computations are selected in the wavelength region of $0.65 \mu \mathrm{m}$ which is applicable for the study of VHRR and VISSR data $(0.6-1.0 \mu \mathrm{m})$. Elterman's values (1968) are adopted for the optical thicknesses of aerosol, Rayleigh and ozone constituents. Deirmendjian model $L$ (1969) is used for the aerosol size distribution with a real index of refraction of 1.34. Computational results show that (1) at a low sun elevation, a high intensity value is noted in the forward direction. This is more pronounced in the case of a specular surface than that of the Lambert surface. (2) At a high sun elevation, an intensity peak exists in the specular direction if the surface is a hybrid mode. (3) For a hybrid surface, the lower the sun elevation, the higher the albedo of the atmosphere-ground system will be. (4) The degree of polarization decreases rapidly with the increase of the Lambert component of reflection. These results reflect the application for parameterizing surface characteristics in terms of the diffuse reflection radiation and hence for monitoring the surface by remote sensing satellite measurements.
\end{abstract}

\section{Introduction}

In the wavelength region $(0.6-1.0 \mu \mathrm{m})$, the atmosphere is rather transparent and hence the radiation reflected directly by the surface is predominant in terms of the diffuse reflection radiation from the atmosphere-ground system, rather than the effect of multiple scattering and absorption due to the atmospheric constituents. Hence this wavelength region is suitable for monitoring the surface characteristic as well as cloud distributions by using remote sensing satellite techniques. In recent years, the development of high resolution radiometers has been making rapid progress and in fact, radiometers such as VHRR and VISSR are engaged in this wavelength region of spectrum. Furthermore the advantage

\footnotetext{
* On leave from the Meteorological Research
} Institute, Tokyo, Japan lies in remote sensing satellite techniques over monitoring the surface characteristics of the earth, such as ice or a sea state or for detecting a snow covered area and deriving its depth where the ground based data is not readily available (Barnes et al., 1972; Wiesnet, 1974; McClain et al., 1969; McClain, 1973). It should also be noted that there are feasibility studies of taking a polarimeter aboard a spacecraft. This is expected to provide a sophisticated knowledge of aerosols and ozone in the atmosphere, as well as surface characteristics. Therefore there is a need to establish the theoretical investigation of these matters, in advance, in terms of the diffuse reflection radiation measurements by using remote sensing satellites.

However in the solution of radiative transfer equations and the computation of the diffuse radiation numerically, the major difficulties lie in the treatment of the effect of multiple scattering 
by aerosols and the multiple interactions between the atmosphere and the ground. Hence, several assumptions are made to model the atmosphereground system to get numerical solutions with a reasonable computation time. The reflected radiation from the ground has usually been discussed, based upon the scattering of light by a Lambert or a specular reflection. However it has recently been discovered in laboratory investigations, that representative samples of natural formations such as soils and sands do not reflect light in accordance with the Lambert law (Chen et al., 1968). The degree of polarization of the radiation reflected by such substances as soil and sand, exhibits a strong dependence on their moisture content (Rao. 1973). Furthermore there is a resiprocal relationship between the surface brightness and the polarization of the reflected radiation. Anisotropic solar reflectance is also observed over white sand, snow and stratus clouds from the Nimbus F-3 medium resolution radiometer (MRIR) (Salomonson et al., 1968). Furthermore fresh fallen snow shows an almost isotropic reflectivity, but the specular component increases with the age of the snowcover (Dirmhirn et al., 1975). These facts necessitate the abandonment of the assumption of a Lambert surface. More sver, optical properties of the surface are expesied to be very important for the diffuse reflestion radiation especially in the long wavelength region of the visible spectrum (Rao et al., $19,3)$. Heace as a representation of the real surface, it is necessary to model the surface to compute the diffuse reflection radiation by the atmosphere-ground system to meet the correspondence between the laboratory measurements and the data taken by satellites. With this reason in mind, the intensity and the degree of polarization of the diffuse reflection radiation by the atmosphere bounded by the hybrid surface of a diffuse and specular reflector is computed. This hybrid surface is in a general expression and hence is applicable for modelling the surface.

\section{Model Atmosphere}

The model atmosphere contains aerosols and ozone distributions with height given by Elterman (1968). The optical thicknesses of the aerosols, Rayleigh particles and ozone are $0.224,0.050$ and 0.021 respectively. Deirmendjian modified Gamma function (model L) (1969) is used for aerosol size distribution $(0.1 \leqq x \leqq 36.0)$, where $x$

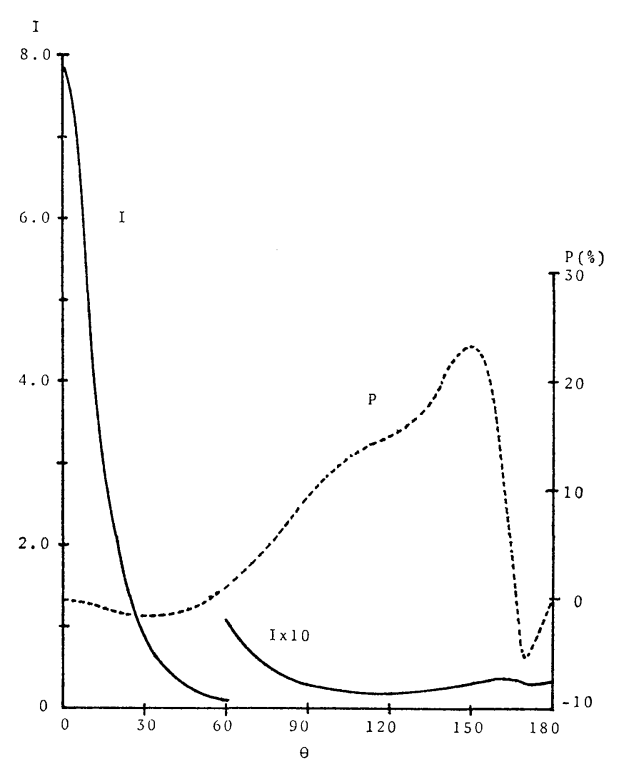

Fig. 1 The intensity (solid line) and the degree of polarization (broken line) of an aerosol single scattering at $\lambda=0.65 \mu \mathrm{m}$ (ordinate). The abscissa represents the scattering angle $\theta$. The polarization degree is defined by $P=\left(I_{r}-I_{1}\right) /\left(I_{r}+I_{1}\right)$ where $I_{r}$ and $I_{1}$ are the intensity, perpendicular and parallel to the plane of scattering. Deirmendjian model $L$ is adopted for the aerosol size distribution with a refractive index $m=1.34$.

represents the size parameter. Since the element $P_{4}$ of the aerosol phase matrix is smaller than that of the other elements, $P_{4}$ is neglected in these computations. The phase function and the degree of polarization are shown in Fig. 1. The refractive index of aerosols is fixed at 1.34 in this study. The wavelength of the radiative transfer is selected as $0.65 \mu \mathrm{m}$, which is applicable to the study of the VHRR and VISSR date $(0.6-1.0 \mu \mathrm{m})$. The reflection matrix of the hybrid surface is defined in the form:

$$
\begin{aligned}
& \boldsymbol{R}\left(A,+\Omega,-\Omega_{0}\right)=4 \mu \mu_{0} A \alpha \boldsymbol{M} \\
& \quad+4 \pi(1-\alpha) \mu_{0} \boldsymbol{R}_{s p}\left(\mu_{0}\right) \delta\left(\mu-\mu_{0}\right) \delta\left(\phi-\phi_{0}\right)
\end{aligned}
$$

where the symbol $\delta$ represents the Dirac delta function indicating that the incident radiation is reflected by the surface only in the specular direction. The $4 \times 4$ matrices $\boldsymbol{M}$ and $\boldsymbol{R}_{s p}\left(\mu_{0}\right)$ represent for Chandrasekhar representation of Stokes vector as follows: 


$$
\boldsymbol{M}=(1 / 2)\left|\begin{array}{cccc}
1 & 1 & 0 & 0 \\
1 & 1 & 0 & 0 \\
0 & 0 & 0 & 0 \\
0 & 0 & 0 & 0
\end{array}\right|
$$

and

$$
\boldsymbol{R}_{s p}\left(\mu_{0}\right)=\left|\begin{array}{cccc}
r_{1}^{2} & 0 & 0 & 0 \\
0 & r_{r}^{2} & 0 & 0 \\
0 & 0 & -r_{1} r_{r} & 0 \\
0 & 0 & 0 & -r_{1} r_{r}
\end{array}\right|
$$

where the reflection coefficients $r_{1}$ and $r_{r}$ are calculated with a refractive index $n=1.33$ (Clarke et al., 1971). The parameters $A$ and $\alpha$ denote the albedo of the diffuse reflector and the ratio of the Lambert surface to that of the specular one respectively. The first term of the right hand side of equation (1) represents the ratio of the Lambert law reflector and the second term does that of the specular reflector. This reflection matrix can be modified by multiplying the arbitrary constant by the terms on the right hand side of equation (1) to model the surface. The diffuse reflection radiation is computed in terms of the inhomogeneous atmosphere which is composed of twelve homogeneous composite layers with fourteen harmonic components. Fig. 2 shows (a) the intensity and (b) the degree of polarization of the radiation reflected by the hybrid surface in the specular direction. It is observed that a diffuse reflector (see Fig. 2(a)) scatters more radiation in the specular direction under the incident illumination at a small nadir angle than at a large nadir angle, while the specular reflector is the opposite of this. It scatters more radiation at a large nadir angle than at a small angle. The reflected radiation is completely polarized at $\theta=53$ if the surface characteristics are of a specular nature (see Fig. 2 (b)). All computations were performed on a CDC 7600 .

\section{Computational results.}

The intensity of the diffuse reflection radiation in the sun vertical is shown in Fig. 3 at the fixed value of albedo $A=0.7$ with changing values of $\alpha$ from 0.0 to 1.0 , where the case of $\alpha=1.0$ corresponds to a pure Lambert surface, while that of $c:=0.0$ a specular reflector. It is evident from the figure that at the sun direction $\theta_{0}=26.0$ (see Fig. 3 (a)) (1) a sharply increased value of intensity exists in the specular direction in the case of

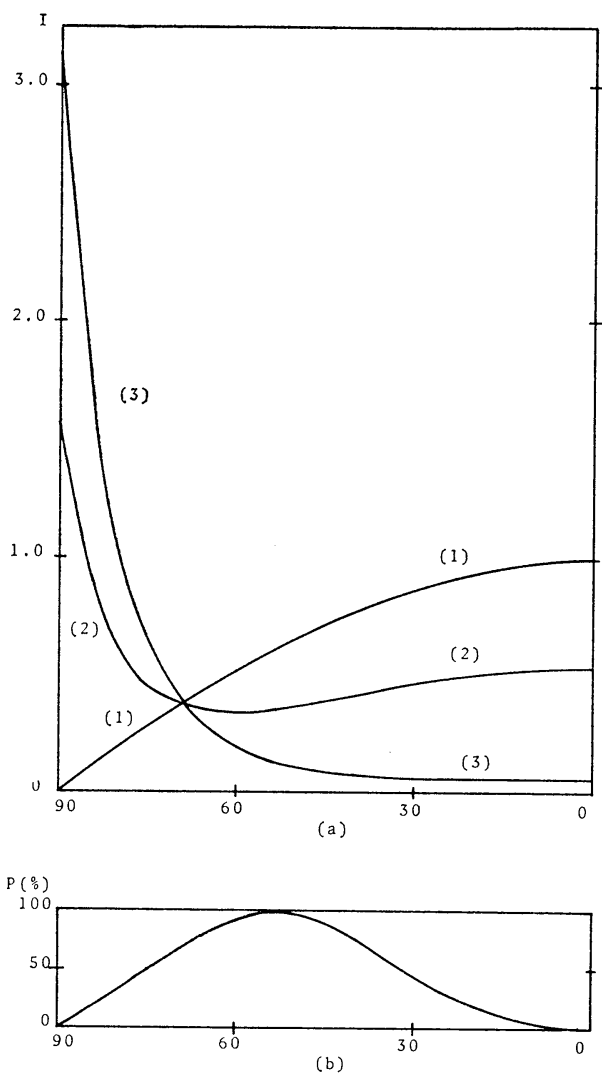

Fig. 2 The radiation ((a) intensity and (b) polarization) reflected by the surface under the illumination with flux $\pi$ (ordinate), where the emergent direction equals the incident direction of illumination. The reflector is assumed to be (1) the Lambert surface ( $A=1.0)$, (2) a hybrid mode $(A=1.0, \alpha=$ $0.5)$ and (3) a specular surface. The abscissa represents the incident direction of radiation.

$\alpha=0.0$ and (2) the intensity is higher at a larger nadir angle of observation. This peak is gradually reduced by increasing the ratio of the Lambert law reflector. In case of the Lambert surface, the intensity is lower at a larger nadir angle of observation and is slightly higher at the antisolar side $(\phi=180)$ than at the solar side $(\phi=0)$.

Fig. 3 (b) shows the same computations as Fig. 3 (a) but for $\theta_{0}=65.9$. At $\alpha=0.0$ the intensity is a larger value at a larger nadir angle of observation, especially on the solar side $(\phi=0)$. This is due to the surface characteristics of the specular law reflector. It reflects a large amount of radiation when the nadir angle of the incident sun is increased (see Fig. 2). At $\alpha=1.0$, the 


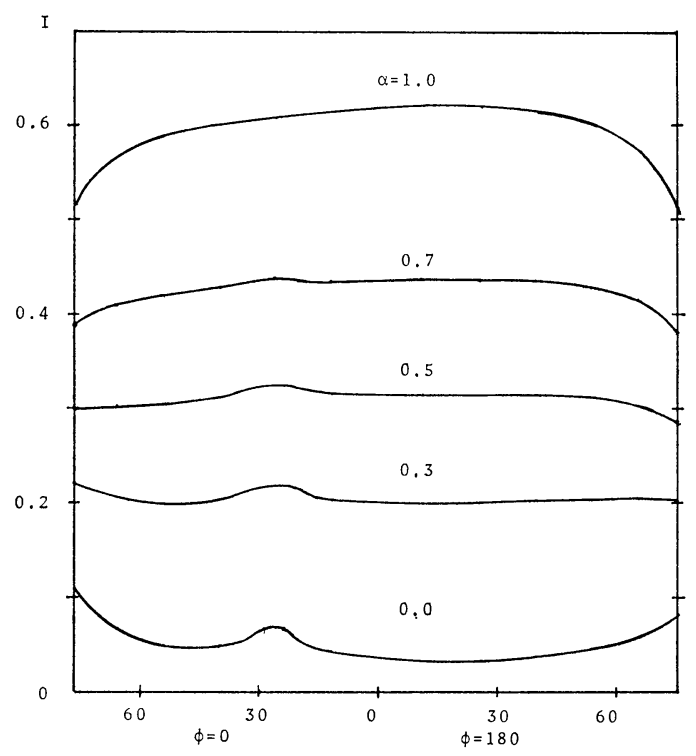

(a)

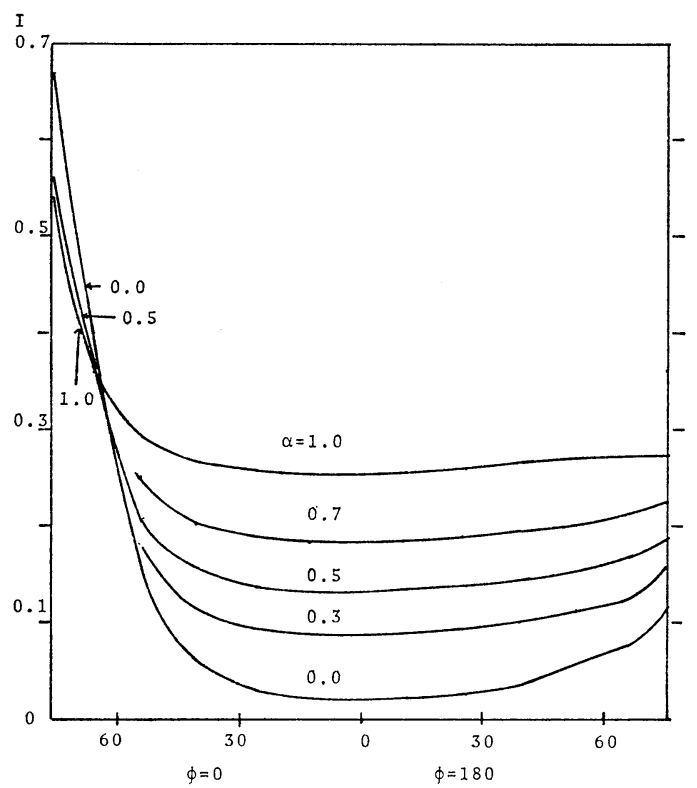

(b)

Fig. 3 The intensity of the diffuse reflection radiation in the sun vertical at $A=0.7$ (ordinate) against nadir angle of observations (abscissa) at the incident sun directions (a) $\theta_{0}=26.0$ and (b) $\theta_{0}=65.9$ (abscissa).

intensity is larger in value at a larger nadir angle of observation on the solar side $(\phi=0)$. The diffuse reflector scatters radiation rather uniformly in all directions, while the specular reflector scatters radiation primarily in the specular direction. Fig. 4 shows the intensity of the diffuse

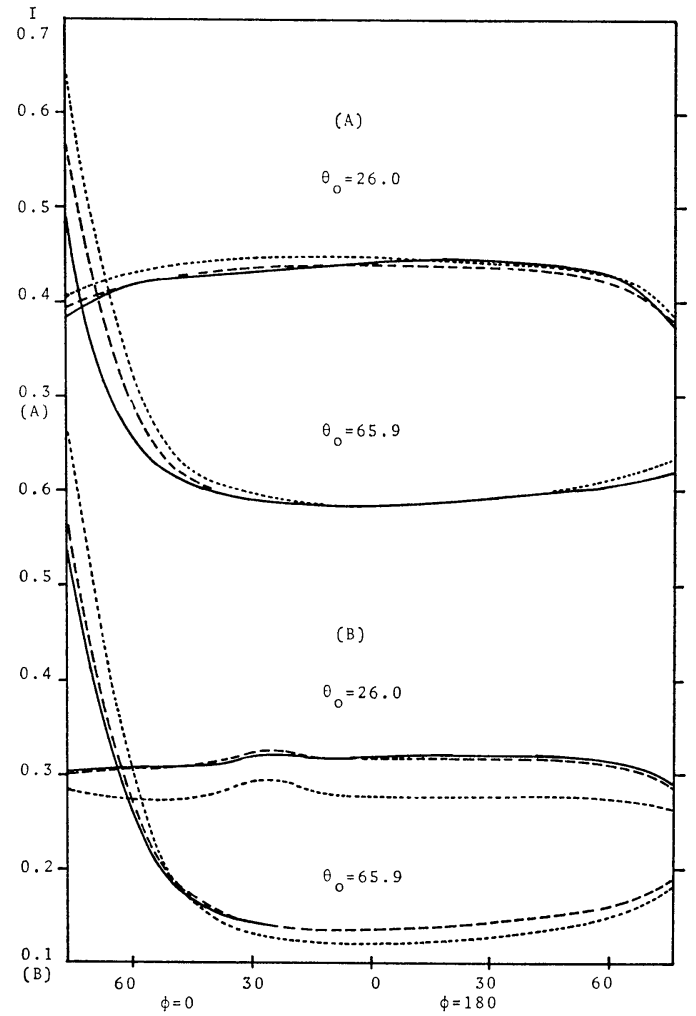

Fig. 4 The intensity of the diffuse reflection radiation in the sun vertical. Solid, long broken and short broken lines correspond to the input data sets (A) $(A=0.5, \alpha=1.0),(A=$ $0.7, \alpha=0.7)$ and $(A=1.0, \alpha=0.5)$, respectively, and, (B) $(A=0.5, \alpha=0.7),(A=0.7$, $\alpha=0.5)$ and $(A=1.0, \alpha=0.5)$, respectively at $\theta_{0}=26.0$ and 65.9 .

reflection radiation in the sun vertical with the input data sets (A) $(A=0.5, \alpha=1.0),(A=0.7$, $\alpha=0.7)$ and ( $A=1.0, \quad \alpha=0.5)$ respectively at selected nadir angles, $\theta_{0}=26.0$ and 65.9. This first data set corresponds to a pure Lambert surface, while the last corresponds to a half of it. At $\theta_{0}=65.9$, a larger intensity value is noted at a larger value of nadir angle of observation, especially in the sun direction $(\phi=0)$. This is more pronounced in the case of $(A=0, \alpha=0.5)$ than in that of $(A=0.5, \alpha=1.0)$. In an observational direction of less than 20 degrees, there is no appreciable difference between these three cases. At $\theta_{0}=26.0$, all three cases show lower values of intensity at larger observation angles, but in the case of $(A=1.0, \alpha=0.5)$ a slightly larger value in the sun direction $(\phi=0)$ is found, while that of $(A=0.5, \alpha=1.0)$ in the anti-sun 
direction. Therefore the hybrid mode is much more realistic than that of a Lambert law to model the surface. Fig. 4(B) shows the same computational results that are shown in Fig. 4 (A), but for the input data sets (B) $(A=0.5, \alpha=$ $0.7),(A=0.7, \alpha=0.5)$ and $(A=1.0, \alpha=0.3)$. It is observed that a larger intensity value exists at a larger nadir angle of observation with the reduction of the value $\alpha$ at $\theta_{0}=65.9$. At $\theta_{0}=26.0$, a small peak of intensity is noted in the specular direction. Hence if the albedo of the diffuse reflector is less than 0.35 and at the same time the contribution of the specular reflector is greater than 50 percent, this small peak can be seen.

Fig. 5 illustrates the angular distribution of the intensity of the diffuse reflection radiation at $A=0.7$ and $\theta_{0}=53.6$ at (1) $\alpha=1.0$, (2) $\alpha=0.5$ and (3) $\alpha=0.0$ in the plane (a) $\phi=0$ and 180 , (b) $\phi=30$ and 150 , (c) $\phi=60$ and 120 and (d) $\phi=90$, respectively. It is observed that at $\alpha=$ 1.0, a high intensity value at a large nadir angle of observation at $\phi=0$ is noted, while on the other hand, at $\phi=180$, a small value is observed. At $0 \leqq \theta \leqq 30$, there is no appreciable difference in intensity values. At $\alpha=0$, a high intensity value exists in all the large nadir angles of observation, especially at $\phi=0$ in the specular direction. At $0 \leqq \theta \leqq 30$, there is no appreciable difference in the intensity value. At $\alpha=0.5$, intermediate values are found. Fig. 6 shows the

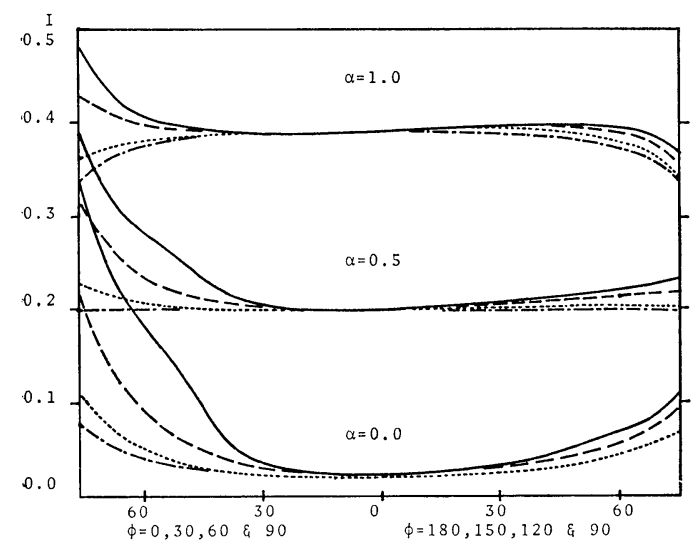

Fig. 5 Angular distribution of intensity of the diffuse reflection radiation at $A=0.7$ and $\theta_{0}=53.6$ for (A) $\alpha=1.0$, (B) $\alpha=0.5$ and (C) $\alpha=0.0$ (ordinate). The abscissa represents the nadir angle of the emergent direction in the planes, $\phi=0-180$ (_ $)$, $\phi=30-150$ (- - -), $\phi=60-120$ (….....) and $\phi=90$ (-•-•-•-).

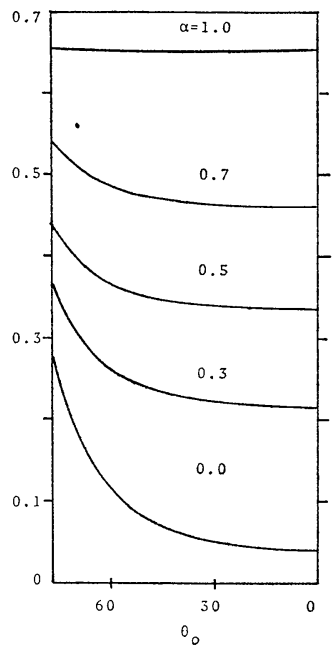

Fig. 6 Albedo as an atmosphere-ground system. The ordinate represents the albedo and abscissa is the solar nadir angle at $A=0.7$ and $\lambda=0.65 \mu \mathrm{m}$. The optical thicknesses of molecules, aerosols and ozone are based on Elterman's data (1968).

albedo of an atmosphere-ground system at a given sun nadir angle $\theta_{0}$ at $A=0.7$. Satellites can measure this quantity with respect to time. From the graph it is observed that if the surface reflects light in accordance with the pure Lambert law, the albedo does not differ appreciably at all sun nadir angles $(A l b .=0.66)$. This is partly due to a high value of the ground albedo $(A=0.7)$ and partly due to a transparent atmosphere $\left(\tau_{\text {tot }}\right.$ $=0.295$ ). But on the other hand, albedo depends on the sun direction to the hybrid surface. It increases rapidly with an increasing sun nadir angle. It is 0.28 at $\theta_{0}=76$ and 0.035 at $\theta_{0}=0$ for a specular reflector.

The degree of polarization of the diffuse reflection radiation in the sun vertical is shown at $A=0.7$ in Fig. 7 (a) $\theta_{0}=11.4$, (b) 40.3 and (c) 65.9, where the parameter $\alpha$ is changed from 0.0 to 1.0. It is observed from the figures (a), (b) and (c) that the degree of polarization is very sensitive in terms of the parameter $\alpha$. It decreases rapidly with the increase of $\alpha,(72 \%$ at $\alpha=0$ and $22 \%$ at $\alpha=0.3$ at $\theta_{0}=40.3$ ). Moreover a higher degree of polarization is observed at $\alpha=0$ and $\theta_{0}=40.3$ than at the other cases $\theta_{0}=11.4$ and 65.9. This is partially due to a higher degree of polarization of the radiation reflected by the specular reflector in the emergent direction and also partly due to a high degree of polarization produced by scattering by the atmospheric con- 


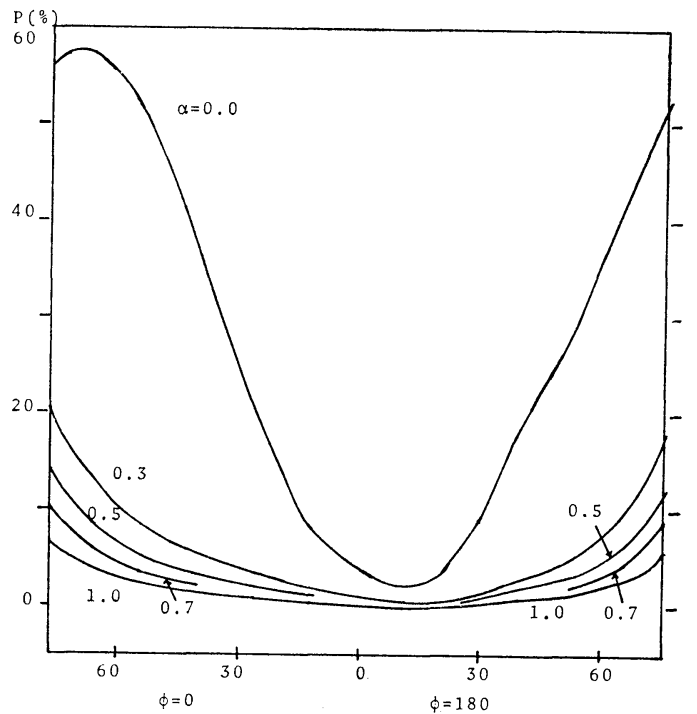

(a)

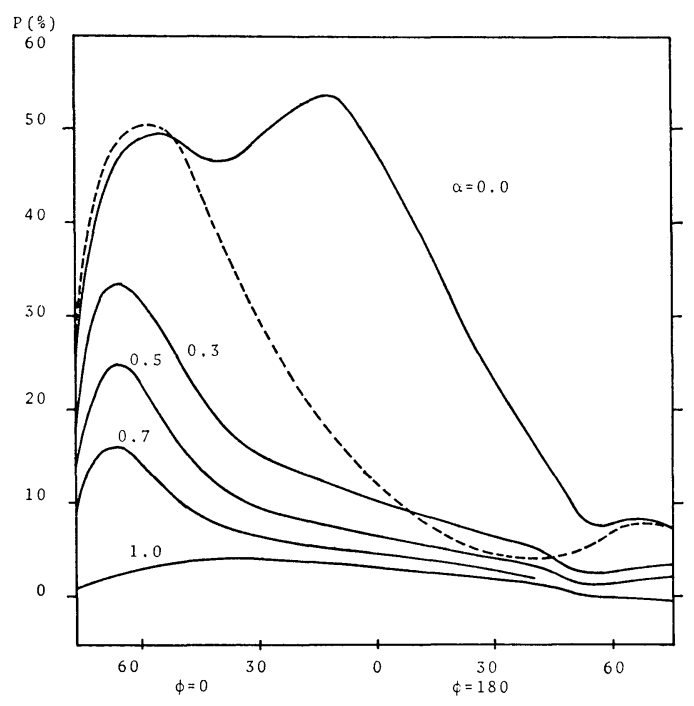

(c)

stituents. These results model the characteristics of the polarization of the radiation produced by the soil and sand with moisture content. With an increased amount of moisture content, a higher degree of polarization was noted in the specular direction (Rao, 1974). In Fig. 7 (c) at $\alpha=0$, the degree of polarization shows the saddle upward in its shape with two high peaks at $\theta=$ 10 and 50. This is due to the combined effect of the multiple scattering processes in the atmosphere and the reflection properties of the surface. If the surface is absent or assumed to reflect no incident radiation, the maximum degree of

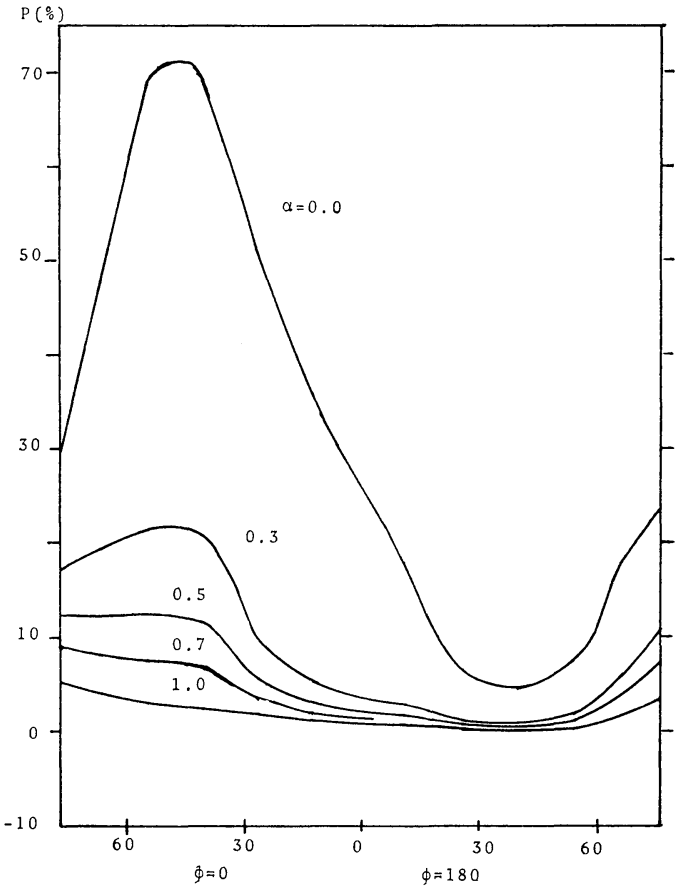

(b)

Fig. 7 The degree of polarization on the diffuse reflection radiation in the sun vertical at $A=0.7$ in a selected sun nadir angles (a) $\theta_{0}=11.4$, (b) 40.3 and (c) 65.9. Dot line in (c) corresponds to the model atmosphere where aerosols do not alter the state of polarization by scattering and furthermore Rayleigh particles are absent.

polarization is expected at around 90 degrees from the anti-sun direction $(\theta=24)$, while in the absence of the atmosphere, the maximum degree of polarization appears in the specular direction $(\theta=66)$. Therefore the degree of polarization of the radiation reflected diffusely by the atmosphereground system turns out to be such a polarization curve due to multiple interaction processes of radiation between the atmosphere and the ground. With an increase in the value of $\alpha$, the peak appears only in the specular direction due to the small value of polarization in terms of the Lambert surface. In fact it is observed from 


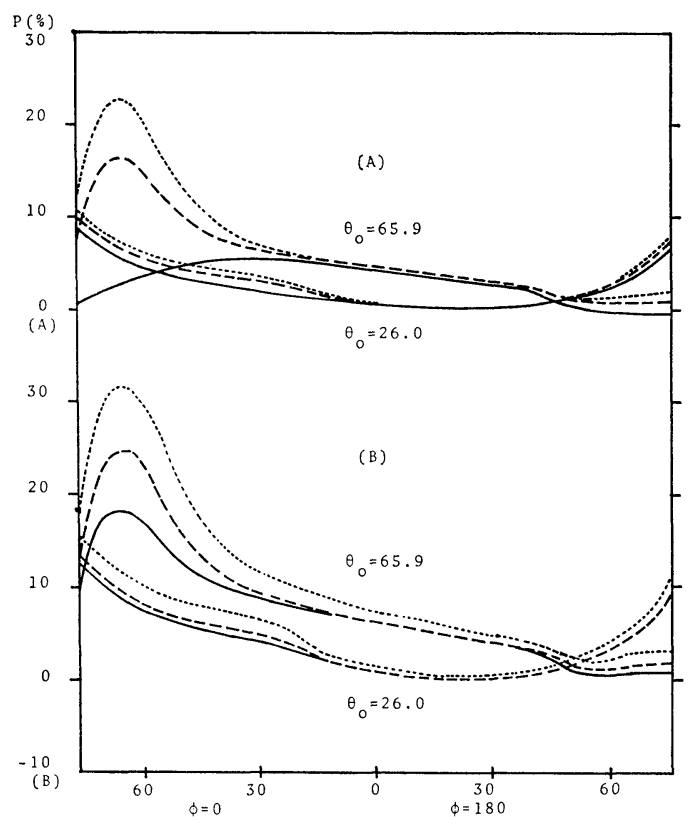

Fig. 8 The same as Fig. 4, but for the degree of polarization.

Fig. 7 (c) that the peak value of polarization at $\theta=10$ disappears if the aerosols do not alter the state of polarization by scattering, and in addition, Rayleigh particles are absent in the model atmosphere (see dot line). Fig. 8 shows the degree of polarization of the radiation emerging from the model atmosphere at the given ratio of a diffuse and specular reflector at (a) $\theta_{0}=65.9$ and (b) 26.0 for the same data set as used in Fig. 4. It is observed from Fig. 8 (A) that (1) a maximum degree of polarization exists in the specular direction at $\theta_{0}=65.9$. This peak reduces very much with the increase of $\alpha$ from 0.5 to 1.0 . (2) A maximum degree of polarization does not exist at $\theta_{0}=26.0$ for the three cases computed, but the polarization value is higher for the data $(A=1.0, \alpha=0.5)$ than that of $(A=0.5, \alpha=1.0)$ due to the surface characteristics. (3) At the Lambert surface the maximum degree of polarization is located at around 90 degrees from the anti-sun direction. It is observed from Fig. 8 (B) that the maximum degree of polarization exists in the specular direction at $\theta_{0}=65.9$, but reduces with an increasing value of the parameter $\alpha$. Hence it is observed that the degree of polarization is a sensitive parameter in terms of the diffuse reflection radiation rather than the intensity. It can provide a knowledge of the surface

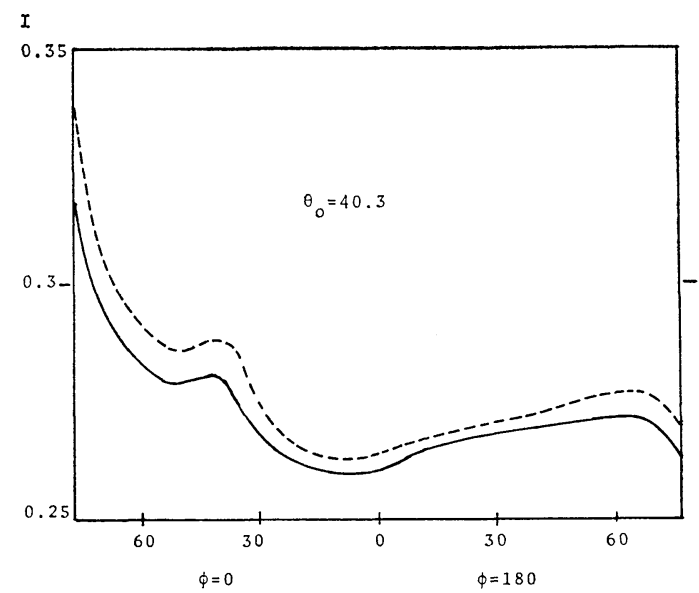

(a)

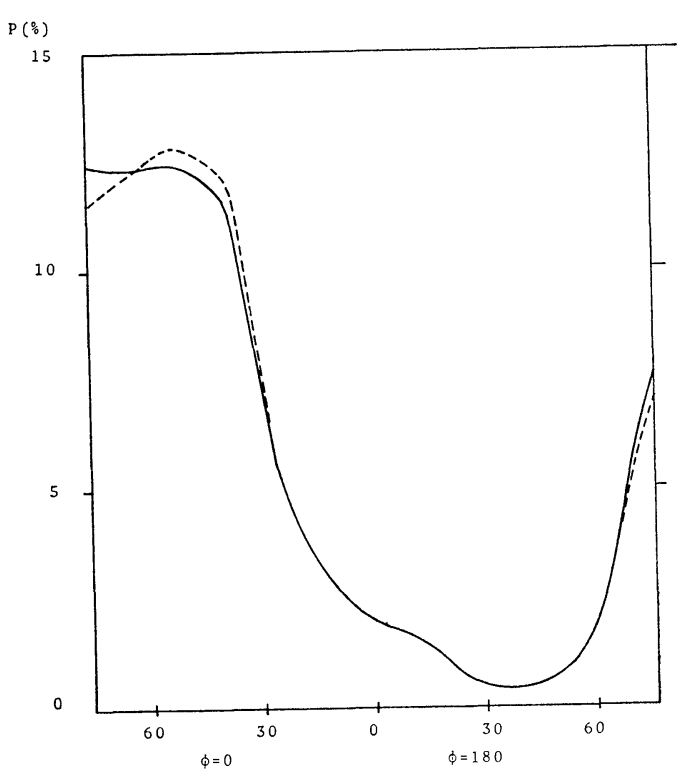

(b)

Fig. 9 Comparison of the intensity (a) and the degree of polarization (b) of the radiation emerging from the inhomogeneous atmosphere (solid line) with that of the homogeneous one at $\lambda=0.65 \mu \mathrm{m}$ for $A=0.7$, $\alpha=0.5$ and $\theta_{0}=40.3$

characteristics in detail. Fig. 9 shows the comparison of the intensity (a) and the polarization degree (b) of the radiation emerging from the inhomogeneous atmosphere with that of the homogeneous one at $A=0.7, \alpha=0.5$ and $\theta_{0}=40.3$. It is observed that the intensity from the homogeneous atmosphere is slightly higher in value than that from the inhomogeneous one, especially 
with a large nadir angle of observation (3.4\% at $\theta_{0}=66,2.4 \%$ at $\theta_{0}=40$ ). The maximum degree of polarization in terms of the homogeneous atmosphere is slightly higher in value $(0.4 \%)$ than that from the inhomogeneous one (see Fig. 8(b)). This is primarily due to the under-estimation of ozone absorption when the assumption of the homogeneous atmosphere is employed. But if the nadir angle of observation is less than $\mathbf{3 0}$ degrees, the intensity deviation is very small $(1.5 \%$ at $\theta=$ $26,1.0 \%$ at $\theta=11$ ). The deviation of the degree of polarization is also very small $(0.13 \%$ at $\theta=$ $66.0,0.54 \%$ at $\theta=40.0$ and $0.20 \%$ at $\theta=26.0$ ). This is partly due to the increased importance of the radiation reflected by the surface in this wavelength region $(\lambda=0.65 \mu \mathrm{m})$. Hence for interpretation of the surface characteristics by using the VHRR data $(\theta=40$ at the sub-synchronous point), the theoretical value of the diffuse reflection radiation by the homogeneous atmosphere can be employed. It should be noted that these results were compared with those of Fraser (1966) for a pure Rayleigh atmosphere bounded by a specular reflector and a perfect agreement was found between them.

\section{Conclusion}

It is found from the theoretical computations that (1) the degree of polarization decreases at the higher ratio of the Lambert law reflector and (2) at the same time the intensity of the diffuse reflection radiation increases. These facts represent the characteristics of the natural formations such as soil and sand with moisture content. Hence a hybrid surface of a diffuse and specular reflector is suitable for modelling these natural formations as well as ice field and snow covered areas, rather than either the Lambert or the specular reflector. It is also found that the computation time required for calculations of the diffuse reflection radiation remains the same as that of either Lambert or specular reflector by using the adding method. Hence it has an advantage in the investigation of surface characteristics, especially in the use of the long wavelength region of the visible spectrum.

\section{Acknowledgements}

The author wishes to express his cordial thanks to Dr. W.L. Godson of the Atmospheric Environment Service, Toronto who provided the NRC fellowship to be able to complete this work. He extends his thanks to Mr. E.G. Morrissey for his encouragement throughout this work. Mr. Andy Hanssen took care of the computations. Special thanks are due to Dr. C.R.N. Rao, Dept. of Meteorology, University of California at Los Angeles and to Dr. Kevin Pang, JPL, California Institute of Technology, Pasadena for their many useful suggestions.

\section{References}

Barnes, J.C., D.T. Chang and J.H. Willand, 1972: Application of ITOS and Nimbus infrared measurements to mapping sea ice, NOAA report, 8 G 93-F.

Chen, H.S., and C.R.N. Rao, 1968: Polarization of light on reflection by some natural surfaces, J. Phys. $D, 1$, pp. 1191-1200.

Clarke, D., and J.F. Grainger, 1971: Polarized light and optical measurement, International Series of monographs in natural philosophy (general editor: D. Ter Haar), 35, Pergamon Press, Oxford.

Deirmendjian, D., 1969: Electromagnetic scattering on spherical polydispersions, American Elserier Publishing Company, Inc., New York.

Dirmhirn, I., and F.D. Eaton, 1975: Some Characteristics of the albedo of snow, J. Appl. Meteor., 14, pp. 375-379.

Elterman, L., 1968: UV, Visible, and IR attenuation for altitudes to $50 \mathrm{~km}$. Air Force Cambridge Research Laboratories, AFCRL-68-0153.

Fraser, R.S., 1966: Theoretical investigation: The scattering of light by a planetary atmosphere, Final report, TRW Space Technology Lab., NASA-CR-76122.

McClain, E.P., 1973: Utilization of earth satellite visible and infrared imagery for determination of snow and sea ice conditions, Meteorological Satellite International Conference, Paris. , and D.R. Baker, 1969: Experimental large-scale snow and ice mapping with composite minimum brightness charts, ESSA Technical Memorandum, NESCTM 12.

Rao, C.R.N., 1974: Dependence of the polarization of radiation reflected by natural formations on index properties, Sixth conference on aerospace and aeronautical meteorology. El Paso, Texas.

T. Takashima and R.B. Toolin, 1973: Measurements and interpretation of the polarization of radiation emerging from the atmosphere at an altitude of $28 \mathrm{~km}$ over south-western New Mexico (USA), Quart. J. R. Met. Soc., 99, pp. 294-302.

Salomonson, V.V., and W.E. Marlatt, 1968: Anisotropic solar reflectance over white sand, snow and stratus clouds, J. Appl. Meteor., 7, pp. 475- 
483.

Takashima, T., C.I. Taggart and E.G. Morrissey, 1975: A hybrid mode of a diffuse and specular reflector on computing the emergent radiation by the "adding" method, To appear in Astrophys.
Space Science.

Wiesnet, D.R., 1974: The role of satellites in snow and ice measurements, NOAA Technical Memorandum, NESS 58.

\section{乱反射と鏡面反射から成る混合反射法則に従う \\ 地面一不均質大気からの反射光について}

高島勉*

(Atmospheric Environment Service, Toronto, Canada)

Adding method (高島その他, 1975) を用いて不均質大気からの散乱反射光の強度と偏光度を計算した. ここで 大気は 12 の homogeneous layers に分割された. 大気〜地面システムにはェアゾール高度分布による散乱光とオゾ ンによる吸収も考虑された。 さらに地面は乱反射抢よび鏡面反射を含む混合反射面とした，この論文では，VHRR やVISSR によるデータ（0.6-1.0 ミクロン） に応用がきくよう 0.65 ミクロン（波長）の所を選んで計算した。 エ アゾール，分子拉よびオゾンの光学的厚さは Elterman (1968) のものを採用した. さらにェアゾールの粒径分布は Deirmendjian (1969) のものを採用した（モデル L. $\mathrm{m}=1.34)$. 計算結果から次のことがわかった.（1）低い太 陽高度の時, 前方方向に強い反射光を認めた。 これた鏡面反射の方が乱反射より一層強いことが分かった.（2）高 い太陽高度の時, もし地面が混合反射面であれば, 鏡面反射方向に強い反射光を認めた。（3）さらに混合反射面で あれば，太陽高度が低ければ一層大気〜地面システムのアルベートが大きくなる（4）偏光度は乱反射の割合が增 加すると急速に減少する。 これらの結果は, 散乱反射光から地表面特性をパラメタライズすることへの応用を意味し 従って人工衛星による地表面モニターへの応用を意味している. 